\title{
Traumatic Pseudoaneurysms of the Head in War Time: Report of Two Unusual Cases
}

\author{
Tayfun HAKAN ${ }^{1,2}$, Ahmet Cemil KAUR ${ }^{3}$ \\ ${ }^{1}$ Ozel Kurtkoy Ersoy Hospital, Neurosurgery Clinic, Istanbul, Turkey \\ ${ }^{2}$ Okan University, Vocational School of Health Services, Istanbul, Turkey \\ ${ }^{3} \mathrm{E}$-patoloji Pathology Laboratory, Uskudar, Istanbul, Turkey \\ These cases have been presented at the $30^{\text {th }}$ Scientific Meeting of Turkish Neurosurgical Society in 8-12 April, 2016, Antalya, Turkey.
}

\section{ABSTRACT}

Intracranial or extracranial pseudoaneurysms due to penetrating head injuries with gunshot are very rare entities. As the pseudoaneurysms of the superficial temporal artery usually present with a pulsating mass lesion beneath the scalp, intracranial pseudoaneurysms are manifested with symptoms including decreased conscious level, seizure, or focal neurological deficits. Here, two patients with combat-related pseudoaneurysms are reported. One was in the distal cortical branch of the anterior cerebral artery and one was in the superficial temporal artery. Both of the cases were victims of the Libyan war. One was admitted with a swelling in his scalp and a pseudoaneurysm on the parietal branch of the superficial temporal artery was diagnosed with computed tomography; and the other was incidentally diagnosed on the distal cortical branch of the anterior cerebral artery during an operation for removal of an intracranial bullet. Both of the aneurysms were treated with surgical excision without any complication.

KEYWORDS: Gunshot injury, Anterior cerebral artery, Penetrating head injury, Pseudoaneurysm, Superficial temporal artery, Traumatic aneurysm

\section{INTRODUCTION}

$\mathrm{P}$ seudoaneurysms emerge with disruption of all three histological layers of the vessel and contain hematoma in a false lumen outside of the vessel and are also known as false aneurysms (20). They are presumably associated with penetrating injuries and in contrast to a true aneurysm do not have an aneurysmal neck. Pseudoaneurysms formed by military munitions used in conflicts of war are well known entities (12). Gunshot wound or blast injury to head may cause traumatic extra- (TECA) or intracranial pseudoaneurysm (TICA) (5). Combat-related traumatic aneurysms located on the distal middle cerebral artery (MCA) or on the superficial temporal artery (STA) are rarely seen $(5,12,22)$. We found only eight cases of pseudoaneurysm located on the distal MCA (M4) and six cases of pseudoaneurysm located on the STA following a gunshot or blast injury in the literature (Table I).
Here, two head-wound patients with a pseudoaneurysm were presented. One of them presented with a palpable mass lesion beneath the skin of the right temporal region and the other with coma.

\section{CASE REPORTS}

\section{Case 1}

A 17-year-old boy, who was a victim of the Libyan civil war, was referred to the intensive care unit for coma 30 hours after sustaining a bullet injury to the right pterional area with an ambulance aircraft. His Glasgow Coma Scale score was 6 on admission. He had undergone debridement of the right pterional region at the local hospital. Computed tomography (CT) revealed an intracerebral hemorrhage with bone fragments from the right to the left hemisphere; the bullet had stopped 
Table I: Pseudoaneurysms Located on the Middle Cerebral Artery or Superficial Temporal Artery Due to Blast or Gunshot Injury Reported in the Literature

\begin{tabular}{|c|c|c|c|}
\hline Author & Mechanism & Location & Entery site \\
\hline \multirow{4}{*}{ Aarabi (1) } & Shell fragment & MCA (M4) & Parietal \\
\hline & Shell fragment & MCA & Temporoparieta \\
\hline & Shell fragment & MCA (M4) & Temporoparieta \\
\hline & Shell fragment & MCA (M4) & Temporoparieta \\
\hline Acosta et al. (2)* & GSW & MCA & Eye \\
\hline \multirow{3}{*}{ Amirjamshidi et al. (3) } & Shell fragment & STA & Multiple site \\
\hline & Shell fragment & STA & Multiple site \\
\hline & Shell fragment & STA & Multiple site \\
\hline \multirow{12}{*}{ Amirjamshidi et al. (4) } & PHI\# & MCA & Pterional \\
\hline & PHI\# & MCA (M4) & Frontal \\
\hline & PHI\# & MCA & Frontal \\
\hline & PHI\# & MCA (M4) & Frontal \\
\hline & $\mathrm{PHI \#}$ & MCA (M4) & Parietal \\
\hline & PHI\# & MCA & Frontal \\
\hline & PHI\# & MCA & Frontal \\
\hline & PHI\# & MCA & Frontal \\
\hline & PHI\# & MCA & Frontal \\
\hline & PHI\# & $\begin{array}{l}\text { MCA } \\
\text { MCA }\end{array}$ & Temporoparieta \\
\hline & PHI\# & MCA & Frontotemporal \\
\hline & PHI\# & $\begin{array}{l}\text { MCA } \\
\text { MCA }\end{array}$ & Parietal \\
\hline \multirow{7}{*}{ Bell et al. (5) } & PHI/Blast injury & STA & Frontal \\
\hline & PHI/Blast injury & MCA & Pterional \\
\hline & PHI/Blast injury & MCA & Frontal \\
\hline & PHI/Blast injury & STA & Frontal \\
\hline & PHI/Blast injury & MCA (M3) & Pterional \\
\hline & PHI/Blast injury & $\begin{array}{c}\text { MCA } \\
\text { MCA (M4) }\end{array}$ & Frontal \\
\hline & GSW & MCA (M4) & Frontal \\
\hline Cox et al. (12) & PHI/Blast injury & STA & Not known \\
\hline Ditmore et al. (13)* & GSW & MCA & Face \\
\hline \multirow{11}{*}{ Haddad et al. (17) } & GSW & $\mathrm{MCA}^{*}$ & Not specified \\
\hline & Shrapnel & $\mathrm{MCA}^{*}$ & Not specified \\
\hline & Shrapnel & MCA & Not specified \\
\hline & Shrapnel & MCA & Not specified \\
\hline & Shrapnel & $\mathrm{MCA}^{*}$ & Not specified \\
\hline & Shrapnel & $\mathrm{MCA}^{*}$ & Not specified \\
\hline & Shrapnel & MCA & Not specified \\
\hline & Shrapnel & $\begin{array}{l}\text { MCA } \\
\text { MCA }\end{array}$ & Not specified \\
\hline & Shrapnel & $\begin{array}{l}\mathrm{MCA}^{*} \\
\mathrm{MCA}\end{array}$ & Not specified \\
\hline & Shrapnel & $\mathrm{MCA}^{*}$ & Not specified \\
\hline & Shrapnel & $\mathrm{MCA}^{*}$ & Not specified \\
\hline
\end{tabular}


Table I: Cont.

\begin{tabular}{|c|c|c|c|}
\hline Author & Mechanism & Location & Entery site \\
\hline 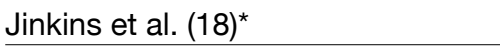 & GSW & MCA & Not specified \\
\hline Lee et al. $(21)^{\star}$ & GSW (pellet) & STA & Multiple site \\
\hline \multirow{2}{*}{ Rahimizadeh et al. (23) } & Shell fragment & MCA & Left side of cranium \\
\hline & Shell fragment & MCA & Zygoma \\
\hline Sadar et al. (24)* & GSW & MCA & Left side of cranium \\
\hline Santos et al. $(25)^{\star}$ & GSW & MCA & Submandibular region \\
\hline $\begin{array}{l}\text { Schmidt-Vanderheyden and Back- } \\
\text { mun }(26)^{\star}\end{array}$ & GSW & MCA & Temporal \\
\hline Spetzler and Owen $(27)^{\star}$ & GSW & MCA & Face \\
\hline \multirow{2}{*}{ Present study } & GSW & MCA (M4) & Parietal \\
\hline & GSW & STA & Temporal \\
\hline
\end{tabular}

GSW: Gunshot wound, MCA: Middle cerebral artery, PHI: Penetrating head injury, PHI\#: Not specified, due to gunshot or blast injury during wartime, STA: Superficial temporal artery, *: Civilian gunshot injury.

at frontal cortex under the skull after traveling through all the right and left frontal lobes (Figure $1 \mathrm{~A}$ ). The patient improved over a 2-month period of intensive care. Seizure attacks that were difficult to control began in the patient although he was under appropriate antiepileptic treatment. A late control CT showed the resolution of hematoma with the bullet in the same location (Figure 1B, C). It was decided to remove the bullet. When the dura was opened and the underlying frontal cortex exposed, the bullet was found to be accompanied by a round hemorrhagic structure presumed to be a pseudoaneurysm (Figure 2A). The bullet and the aneurysmal structure were removed with microsurgical techniques; the aneurysm wall had a close relationship to a small bone fragment that had come there with the bullet (Figure 2B). The histological examination of the aneurysm showed no vessel wall layer and it was diagnosed as a pseudoaneurysm (Figure 2C). The pseudoaneurysmal dilatation was full of hemorrhage with peripheral organized tissue.

\section{Case 2}

A 24-year-old man, who was a victim of the Libyan civil war, was admitted with a slow-growing swelling in his right temporal area. He was wounded from his chin and head during a conflict 45 days ago. He was neurologically intact; a round and pulsating mass measuring $2 \times 1.5 \mathrm{~cm}$ beneath scar tissue in his right temporal region was detected on physical examination. A CT-angiogram investigation showed a lesion with contrast enhancement on the parietal branch of the STA, supporting our presumed diagnosis of pseudoaneurysm (Figures 3A-C; $4 A, B)$. The lesion was explored and removed by excision under local anesthesia. The histological examination of the aneurysm showed no vessel wall layer and it was diagnosed as a pseudoaneurysm (Figure $3 A-C$ ).

\section{DISCUSSION}

The true incidence of conflict-related TICAs or TECAs is still uncertain (5). Ferry and Kempe found only two pseudoaneu- rysm cases among 2,187 casualties in the Vietnam War (15), and Chadduck found none among 879 cases of craniocerebral injury in the Korean Conflict (10). Rahimi-Movaghar et al. collected 177 cases of traumatic aneurysm due to gunshot injury in their review of the literature in 2013 (22). After that report, we found one TICA (9), and one TECA on STA (21); and a series of 11 patients with 13 TECAs reported by Cox et al. which was dismissed in that study (12). Although the patients presented in this report were victims of the Libyan civil war, we did not have any data regarding the number of patients with penetrating head injuries and any other possible traumatic aneurysms during that war.

Penetrating vascular injuries can behave differently even in the same patient regarding their occurrence, evaluation or regression (21). It was found that the incidence of TICA formation was significantly higher when the site of entrance was the orbitobasal and frontal regions (4), and in presence of accompanying intracranial hematomas in penetrating head injuries (7). Bodanapally et al. found a statistically significant correlation between bi-hemispheric injury and occurrence of traumatic aneurysms (8). Intracranial aneurysm formation was not always associated with a penetrating injury and bone fragment entry site $(4,5)$. The aneurysm of the first case reported here was located opposite to the bullet entrance site.

An acutely decreased conscious level, seizure, or focal neurological deficits are the most common symptoms of clinical presentation of TICAs (20). As TICAs usually cause immediate or delayed intracranial bleeding, pseudoaneurysms on STA often present with pulsatile mass lesions that progressively grow in size $(19,28)$. As pointed above, the cases reported in this study presented with seizure attacks and a pulsatile growing mass lesion for the TICA and STA aneurysm respectively.

In particular cases of penetrating head injuries, angiography was recommended to rule out the delayed formation of traumatic intracranial aneurysm (20). In case of acute head injury, CT is the procedure of choice, so early diagnosis of 
pseudoaneurysm may be ignored (16); for this reason any patient who has a penetrating head injury through frontobasal or pterional window (5), or when the missile passes from one hemisphere to the other (4), is advised to undergo diagnostic angiography. However, in the acute stage, even digital subtraction angiography (DSA) may not show any aneurysm formation due to presence of associated hemorrhage lesions and/or aneurysm formation could take time (25). The limitation of the first case reported here was not to use CT-angiography or DSA for detecting any possible vascular injury. Doppler ultrasonography (DU) and/or CT-angiography may be sufficient for detecting STA aneurysm $(19,22)$. In the second case, CTangiography definitely revealed a pseudoaneurysm of the STA. There is no study reporting routine use of magnetic resonance imaging (MRI) for the diagnosis of pseudoaneurysm. MRI/ MR-angiography is advised for the patients with recurrent epistaxis and progressive cranial nerve palsy following a head injury, followed by DSA if a suspicious lesion is found (20). Bhaisora et al. reported that MR-angiography with time of flight (TOF) sequence can be used in traumatic aneurysms of the intracranial vessels with nearly $90 \%$ accuracy (6). A pseudoaneurysm may show contrast enhancement in T1weighted images, and hyperintense core and hypointense rim representing hemosiderin on T2-weighted images $(11,14)$.

Aggressive surgical management of the TICAs was advised as the most appropriate treatment (20). The surgical treatment of TICAs includes clip application (5), resection (4), trapping (20), and endovascular treatment $(5)$ - coil embolization $(9,16)$, glue embolization or stent $(8,21)$. Pseudoaneurysms are usually not suitable for clipping because they not have a true neck formation (4). In the present report, the pseudoaneurysm
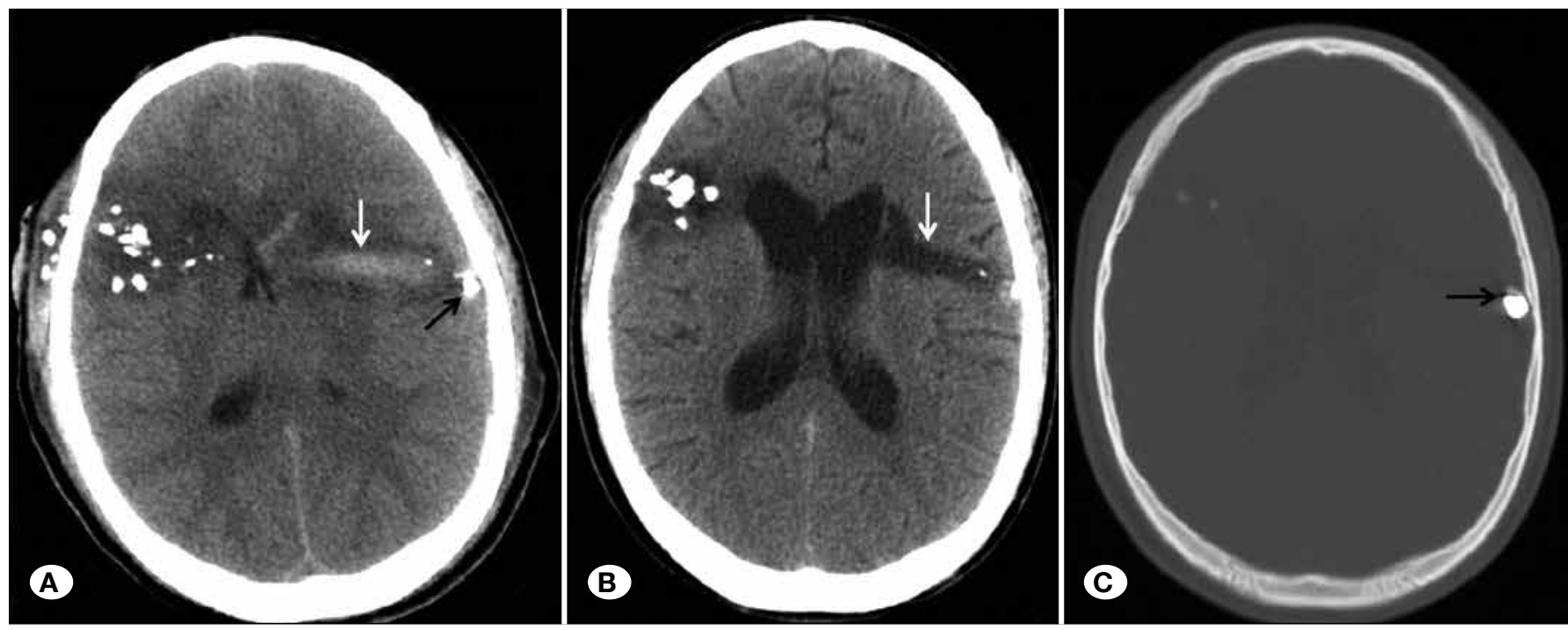

Figure 1: A) Multiple bone fragments in the right frontal lobe, collapsed lateral ventricles, intracerebral hemorrhagic contusion in the left frontal lobe (white arrow) and bullet and accompanying bone fragment in the left frontal cortex (black arrow) on initial CT scan of the patient, B) multiple bone fragments in the right frontal lobe and slightly enlarged lateral ventricles, hypodense area due to the resorption of the hemorrhagic contusion in the left frontal lobe (white arrow) in the follow-up CT scan after 2 months, C) bullet and accompanying bone fragment (black arrow) in bone-window CT scan.
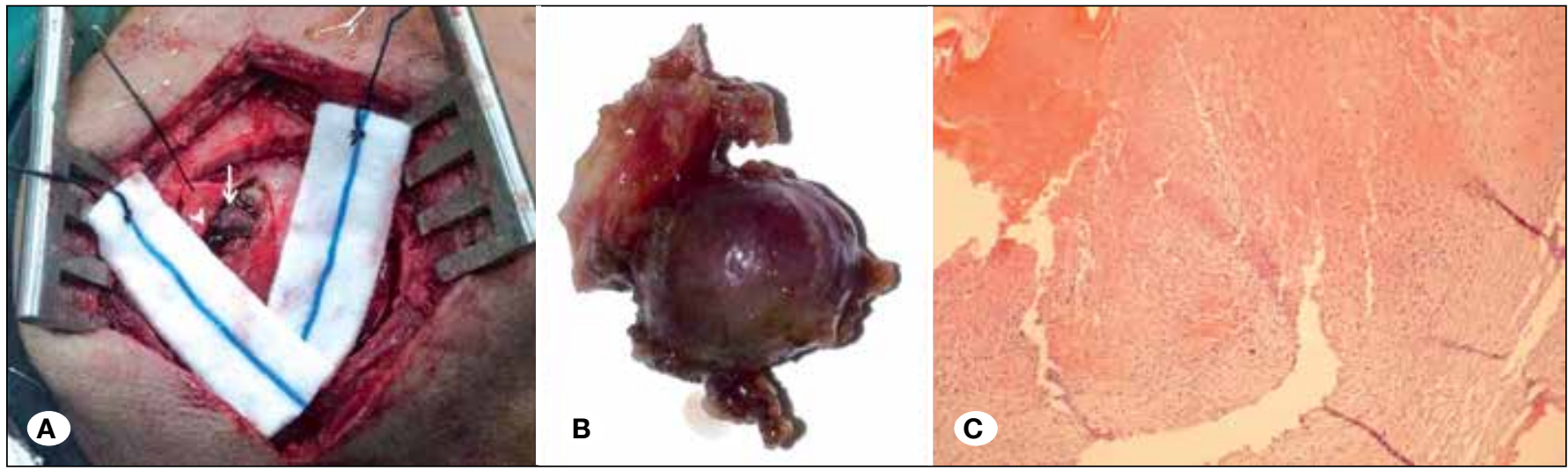

Figure 2: A) Bullet (arrow head) and aneurysm (arrow) in operation field, B) pseudoaneurysm and accompanying bone fragment after resection, C) hemorrhagic area in the pseudoaneurysmal dilatation with peripheral organized tissue $(H \& E, x 200)$. 
located on the cortical artery that was diagnosed during removal of a bullet was excised without any complication. Dissection and excision of the aneurysm is also recommended for treatment of STA aneurysms (28). Endovascular embolization $(12,21)$, and digital compression that cause thrombosis of the aneurysm (19) are the other treatment modalities.

\section{CONCLUSION}

Although they are rare entities, intracranial or extracranial pseudoaneurysms should be considered in patients with penetrating head injuries by military munitions. A CTangiogram or DSA for intra- and/or extracranial and DU for extracranial penetrating traumas can be used for diagnosis. The pseudoaneurysm can be definitely and safely treated with surgical excision.
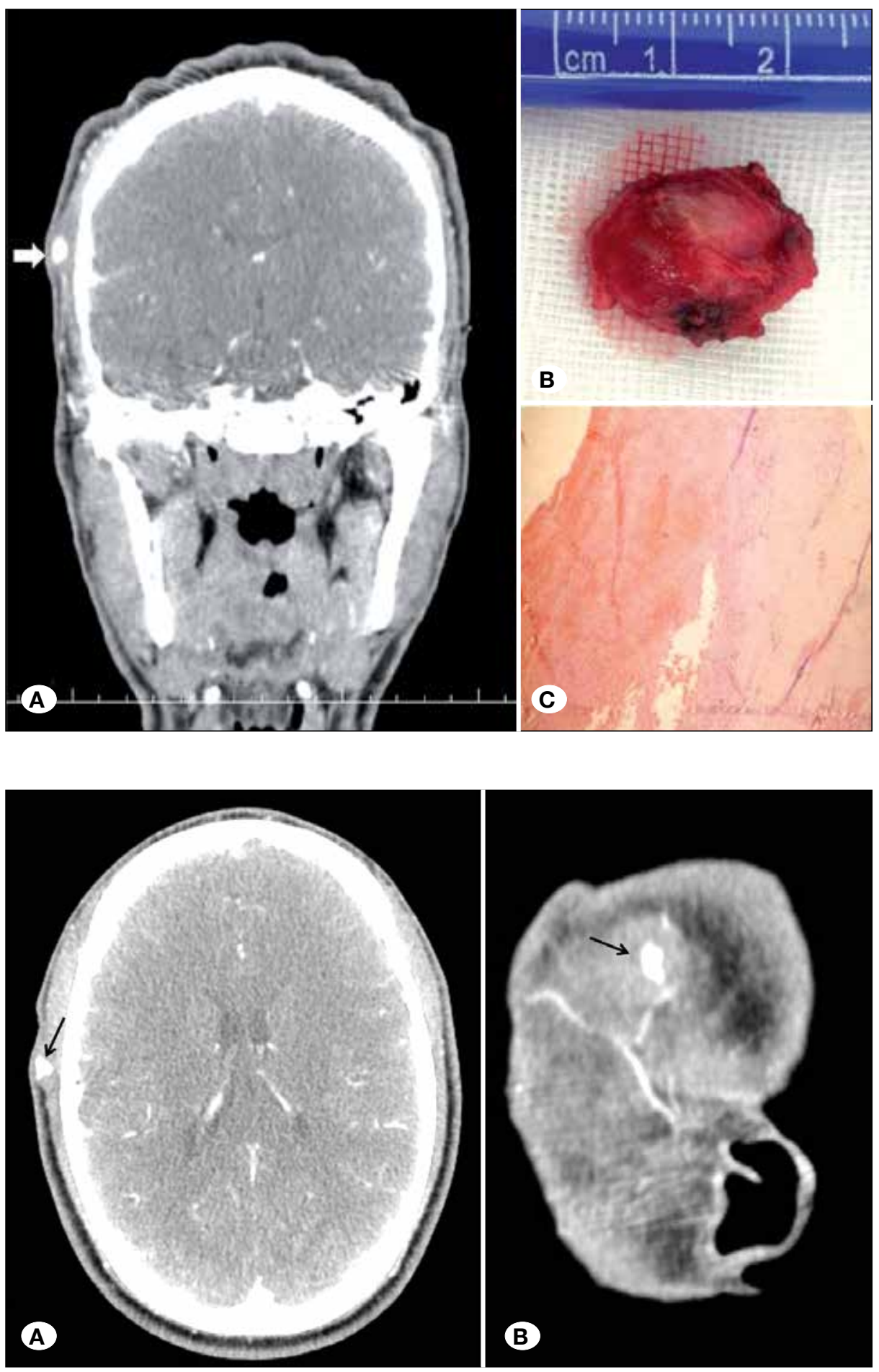

Figure 3: A) Coronal CT-angiogram of the pseudoaneurysm of the parietal branch of the right superficial temporal artery, B) photograph of the pseudoaneurysm just after the resection, C) organized hematoma composing the pseudoaneurysm (H\&E, x200).
Figure 4: A) The CT-angiogram of the pseudoaneurysm in the right temporal extracranial area on axial image (black arrow). B) The CT-angiogram of the pseudoaneurysm located on the parietal brunch of the right superficial temporal artery on sagittal image (black arrow). 


\section{REFERENCES}

1. Aarabi B: Traumatic aneurysms of brain due to high velocity missile head wounds. Neurosurgery 22:1056-1063, 1988

2. Acosta C, Williams PE Jr, Clark K: Traumatic aneurysms of the cerebral vessels. J Neurosurg 36:531- 536, 1972

3. Amirjamshidi $\mathrm{A}$, Abbassioun $\mathrm{K}$, Rahmat $\mathrm{H}$ : Traumatic aneurysms and arteriovenous fistulas of the extracranial vessels in war injuries. Surg Neurol 53:136-145, 2000

4. Amirjamshidi $\mathrm{A}$, Rahmat $\mathrm{H}$, Abbassioun $\mathrm{K}$ : Traumatic aneurysms and arteriovenous fistulas of intracranial vessels associated with penetrating head injuries occurring during war: Principles and pitfalls in diagnosis and management. A survey of 31 cases and review of the literature. J Neurosurg 84(5):769-780, 1996

5. Bell RS, Vo AH, Roberts R, Wanebo J, Armonda RA: Wartime traumatic aneurysms: Acute presentation, diagnosis, and multimodal treatment of 64 craniocervical arterial injuries. Neurosurgery 66(1):66-79, 2010

6. Bhaisora KS, Behari S, Godbole C, Phadke RV: Traumatic aneurysms of the intracranial and cervical vessels: A review. Neurol India 64 Suppl: S14-S23, 2016

7. Bizhan A, Mossop C, Aarabi JA: Surgical management of civilian gunshot wounds to the head. Handb Clin Neurol 127:181-193, 2015

8. Bodanapally UK, Saksobhavivat N, Shanmuganathan K, Aarabi B, Roy AK: Arterial injuries after penetrating brain injury in civilians: Risk factors on admission head computed tomography. J Neurosurg 122(1):219-226, 2015

9. Bonfield CM, Grandhi R, Jankowitz BT, Tyler-Kabara EC: Traumatic intracranial aneurysm after penetrating brain trauma. BMJ Case Rep 2014. pii: bcr2014206130. doi: 10.1136/bcr-2014-206130

10. Chadduck WM: Traumatic cerebral aneurysm due to spear gun injury. J Neurosurg 31: 77-79, 1969

11. Cho WS, Batchuluun B, Lee SJ, Kang HS, Kim JE: Recurrent subdural hematoma from a pseudoaneurysm at the cortical branch of the middle cerebral artery after mild head injury: Case report. Neurol Med Chir (Tokyo) 51(3): 217-221, 2011

12. Cox MW, Whittaker DR, Martinez C, Fox CJ, Feuerstein IM, Gillespie DL: Traumatic pseudoaneurysms of the head and neck: Early endovascular intervention. J Vasc Surg 46(6): 1227-1233, 2007

13. Ditmore QM, Samson DS, Beyer CW: Traumatic middle cerebral artery aneurysm: Case report. Neurosurgery 6: 293296, 1980

14. Dubey A, Sung WS, Chen YY, Amato D, Mujic A, Waites $P$, Erasmus A, Hunn A: Traumatic intracranial aneurysm: A brief review. J Clin Neurosci 15(6): 609-612, 2008
15. Ferry DJ, Kempe LG: False aneurysm secondary to penatration of the brain through orbitofacial wounds. J Neurosurg 36: 503-506, 1972

16. Hachemi M, Jourdan C, Di Roio C, Turjman F, Ricci-Franchi A, Mottolese C, Artru F: Delayed rupture of traumatic aneurysm after civilian craniocerebral gunshot injury in children. Childs Nerv Syst 23(3): 283-287, 2007

17. Haddad FS, Haddad GF, Taha J: Traumatic intracranial aneurysms caused by missiles: Their presentation and management. Neurosurgery 28: 1-7, 1991

18. Jinkins JR, Dadsetan MR, Sener RN, Desai S, Williams RG: Value of acute-phase angiography in the detection of vascular injuries caused by gunshot wounds to the head: Analysis of 12 cases. AJR Am J Roentgenol 159: 365-368,1992

19. Kim JH, Jung YJ, Chang $\mathrm{CH}$ : Superficial temporal artery pseudoaneurysm treated with manual compression alone. J Cerebrovasc Endovasc Neurosurg17(1): 49-53, 2015

20. Larson PS, Reisner A, Morassutti DJ, Abdulhadi B, Harpring JE: Traumatic intracranial aneurysms. Neurosurg Focus 8(1):e4, 2000

21. Lee SR, Metwalli ZA, Yevich SM, Whigham CJ, Benndorf G: Variability in evolution and course of gunshot injuries to the neck and impact on management. A case report. Interv Neuroradiol 19(4): 489-495, 2013

22. Rahimi-Movaghar V, Jazayeri SB, Alimi M, Abbassioun $\mathrm{K}$, Amirjamshidi A: Lessons learned from war: A comprehensive review of the published experiences of the Iranian neurosurgeons during the Iraq-Iran conflict and review of the related literature. World Neurosurg 79(2): 346-358, 2013

23. Rahimizadeh A, Abtahi H, Daylami MS, Tabatabei MA, Haddadian K: Traumatic cerebral aneurysms caused by shell fragments. Report of four cases and review of the literature. Acta Neurochir (Wien) 84: 93-98, 1987

24. Sadar ES, Jane JA, Lewis LW, Adelman LS: Traumatic aneurysms of the intracranial circulation. Surg Gynecol Obstet 137: 59-67, 1973

25. Santos G, Lima T, Pereira S, Machado E: Traumatic middle cerebral artery aneurysm secondary to a gunshot wound. J Neuroimaging 23(1):115-117, 2013

26. Schmidt-Vanderheyden W, Backmund H: Angiographic observations of the development of a traumatic intracerebral aneurysm. Arch Psychiatr Nervenkr (1970) 214(1): 10-16, 1971 (In German)

27. Spetzler RF, Owen MP: Extracranial-intracranial arterial bypass to a single branch of the middle cerebral artery in the management of a traumatic aneurysm. Neurosurgery 4:334337,1979

28. Stapleton CJ, Fusco MR, Thomas AJ, Levy El, Ogilvy CS: Traumatic pseudoaneurysms of the superficial temporal artery: Case series, anatomy, and multidisciplinary treatment considerations. J Clin Neurosci 21(9): 1529-1532, 2014 